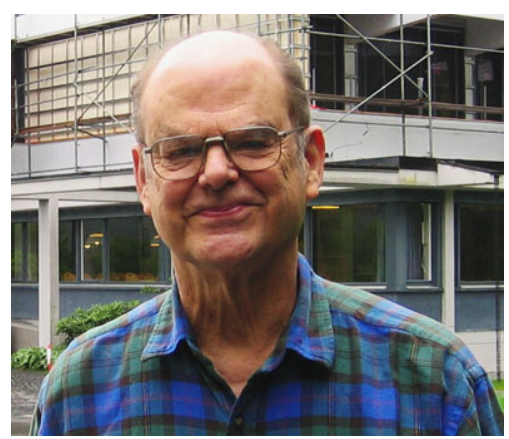

\title{
Curriculum Vitae for John Griggs Thompson
}

\author{
Born: $\quad$ October 13, 1932 in Ottawa, USA
}

Degrees/education: Bachelor, Yale University, 1955

$\mathrm{PhD}$, University of Chicago, 1959

Positions: $\quad$ Assistant Professor, Harvard University, 1959-1962

Professor, University of Chicago, 1962-1970

Rouse Ball Professor of Mathematics, University of Cambridge, 1970-1993

Graduate Research Professor, University of Florida, 1993-

Memberships: $\quad$ National Academy of Sciences, USA, 1967

Royal Society of London, 1979

American Academy of Arts and Sciences, 1998

Accademia Nazionale dei Lincei,

Norwegian Academy of Science and Letters, 2008

Awards and prizes: Cole Prize, 1965

Fields Medal, 1970

Senior Berwick Prize, 1982

Sylvester Medal, 1985

Poincaré Medal, 1992

Wolf Prize, 1992

National Medal of Science, US, 2000

Abel Prize, 2008

Honorary degrees: University of Illinois, 1968

Yale University, 1985

University of Oxford, 1987

Ohio State University, 2009 